\title{
CORTICOSTEROID THERAPY IMPACTS MORTALITY IN COVID-19 PATIENTS: A META-ANALYSIS
}

\author{
Atika Mima Amalin \\ Masters Program in Public Health, Universitas Sebelas Maret
}

\begin{abstract}
Background: Corticosteroids constitute a group of anti-inflammatory and immunosuppressive drugs that are widely used in the treatment of COVID-19. However, corticosteroid use has been the subject of debate. The available evidence the effect of corticosteroid on the mortality in COVID-19 patients is uncertain, and knowledge on the subject is evolving. A systematic review and meta-analysis was conducted to investigate the impact of corticosteroid therapy on the mortality of COVID-19 patients.

Subjects and Method: A systematic review and meta-analysis was conducted by collecting articles from PubMed, Google Scholar, and Science Direct databases. The inclusion criteria were English full text and cohort study. The articles were filtered using PICO model, including: (1) Population= confirmed COVID-19 patients, (2) intervention $=$ corticosteroid therapy, (3) comparison= non corticosteroid therapy, and (4) outcome $=$ mortality. The inclusion criteria were English full text and reported adjusted hazard ratio. Quantitative data analysis was processed using Review Manager 5.3.

Results: A meta-analysis involved 7 studies showed that corticosteroid intake reduced the risk of death in COVID-19 patients ( $\mathrm{aHR}=0.62 ; 95 \% \mathrm{CI}=0.52$ to $0.75 ; \mathrm{p}<0.001)$.

Conclusion: Corticosteroid intake reduces the risk of death in COVID-19 patients.
\end{abstract}

Keywords: cortikosteroid therapy, mortality, COVID-19.

\section{Correspondence:}

Atika Mima Amalin. Masters Program in Public Health in Public Health, Universitas Sebelas Maret. Jl. Ir. Sutami 36A, Surakarta 57126, Central Java. Email: atikamima125@gmail.com. Mobile: 085767052088. 